\title{
Electroanalysis and electrocatalysis using poly(vinylferrocenium) perchlorate coated electrodes
}

\author{
Handan Gülce ${ }^{1}$, Serdar S. Çelebi ${ }^{2}$, Haluk Özyörük ${ }^{1}$ and Attila Yıldız ${ }^{1 *}$
}

1.Hacettepe University, Department of Chemistry, Beytepe, Ankara, 06532 Turkey

2. Hacettepe University, Department of Chemical Engineering, Beytepe, Ankara, 06532 Turkey

\begin{abstract}
Electroanalytical applications based on the electrochemical behavior of the redox polymer, poly(vinylferrocenium) perchlorate $\left(\mathrm{PVF}^{+} \mathrm{ClO}_{4}{ }^{-}\right)$coated as a film on $\mathrm{Pt}$ surfaces, are described. This chemically modified surface is electroactive due to the existence of ferrocenium/ferrocene sites in its structure. Electrooxidation and electroreduction of other depolarizers can also take place through this polymeric film. Anions such as iodide, thiocyanate and cyanide are incorporated in the polymeric structure as a result of anion exchange. Anodic stripping of the anions from the film can be carried out after the initial preconcentration. Catalytic reduction and oxidation of anthracene occur on the $\mathrm{PVF}^{+} \mathrm{ClO}_{4}{ }^{-}$coated $\mathrm{Pt}$ surface in acetonitrile/TBAP medium. An enzyme such as glucose oxidase could be immobilized in the polymeric matrix and this surface could be used for the amperometric determination of glucose under aerobic conditions. Coimmobilization of two enzymes, glucose oxidase and invertase, in the same polymeric matrix allows for the development of an amperometric sucrose sensor.
\end{abstract}

\section{INTRODUCTION}

The metal surfaces that are coated with polymeric films are examples of chemically modified electrodes. These surfaces are intensively investigated because of the possibilities they offer in the fields of electrocatalysis and electroanalysis. The polymeric material may be chosen so that it can intrinsically conduct electricity. The electrical conductance may arise from the presence and movement of the radicalic or charge defect sites (solitons or polarons) within the $\pi$-electronic structure of the polymer. These class of compounds are called conducting polymers or organic metals. Another types of macrostructures which are named as redox or electroactive polymers contain a pair of reduced and oxidized groups and the hopping of electrons between these redox pairs is the reason for the electrical conductance. $\mathrm{PVF}^{+} \mathrm{ClO}_{4}{ }^{-}$is a good example for the latter type of conducting materials [1-8] and studies revealed the evidence for the existence of the ferrocenium as well as ferrocene centers in the structure [9]. In addition to its own electroactivity that is caused by this redox pair, diffusion of other electroactive species through the film and subsequent charge transfer at the metallic surface underneath can also take place $[1,10]$. The redox centers in the structure can also act as mediator for the charge transfer from substrate to some depolarizers [10]. The type of the solvent, the nature of the electrolyte and its concentration affect the rates of the electron transfer between the electroactive sites and the diffusion of the other depolarizers through the film [11]. The model that interprets the electrochemical properties of this interesting material should take into account the rate of interconversion of the oxidized $\left(\mathrm{PVF}^{+}\right.$) and reduced (PVF) centers in the structure, the rates of diffusion of the depolarizers through the film and the counter ions within the film and the rates of various charge transfer processes between the substrate, the film and the depolarizer [12].

We review in this paper the results obtained in our laboratory related to the electrochemical and electrocatalytic properties and the electroanalytical applications of this polymeric material when used as a chemically modified electrode.

\section{EXPERIMENTAL}

Poly(vinylfertocene) is prepared by chemical polymerization of its monomer, vinylferrocene, at $70^{\circ} \mathrm{C} .2,2^{\prime}-$ Azo-bis (2-methylpropionitrile) was used an initiator. Polymerization was carried out for 24 hours. Electroprecipitation of this neutral polymer was accomplished by electrolysis at constant potential $(0.7 \mathrm{~V}$ vs. $\mathrm{Ag} / \mathrm{AgCl}$ ) in methylene chloride/0.1 M TBAP. The charge passed during this electrolysis was related to

\section{*Corresponding author}


the thickness of the film obtained [10]. For example, $1 \times 10^{-3} \mathrm{C}$ of charge corresponded to $1.32 \times 10^{-6} \mathrm{~mol}$ of $\mathrm{PVF}^{+} \mathrm{ClO}_{4}^{-}$per $\mathrm{cm}^{2}$ ( $3 \times 10^{5}$ layers or $\sim 300 \mu \mathrm{m}$ of dry thickness).

The nature of the polymeric film and the changes occuring in its structure were followed by IR or UV spectroscopy and DSC measurements. $\mathrm{KBr}$ pellets of the film were prepared for IR measurements. The sample solutions of the film were prepared in DMF for UV spectroscopic studies. DSC measurements of the films were carried out under nitrogen atmosphere.

The anion exchange between the film and the solution containing anions was accomplished by immersing the $\mathrm{PVF}^{+} \mathrm{ClO}_{4}{ }^{-}$coated $\mathrm{Pt}$ surface in stirred solution for 15 minutes. Enzymes in anionic form were incorporated into the film by immersing $\mathrm{PVF}^{+} \mathrm{ClO}_{4}{ }^{-}$coated surface in stirred solutions containing the corresponding enzymes for 30 minutes. The anion exchanged or enzyme loaded surfaces were rinsed with triple distilled water after anion exchange. The $\mathrm{pH}$ of the glucose oxidase solutions and that of glucose oxidase and invertase mixed-solution were kept at $\mathrm{pH}$ 7.4. This $\mathrm{pH}$ value was well above the isoelectric point of the individual enzymes and both of the enzymes exist as anions at this $\mathrm{pH}$. The enzymes attached to the electrode surface were rinsed with a $0.01 \mathrm{M}$ buffer solution that has the corresponding working $\mathrm{pH}$ value for 15 minutes to remove the remains of the enzymes that were held nonelectrostatically by the polymer surface. For the determination of the steady state background current value in constant potential electrolysis, the potential that is beyond the $\mathrm{H}_{2} \mathrm{O}_{2}$ oxidation peak value was applied to the enzyme electrode which was kept in the same buffer solution. After the steady state background value was determined known amounts of substrate were added to the cell from stock solution and the steady state response of the electrode was determined. The enzyme electrodes were kept in a buffer solution at $4^{\circ} \mathrm{C}$ overnight before use and when not in use. Further details related to the experimentation were already published $[15,16,17]$.

Electrochemical cell was a three electrode type with separate compartments for the reference $(\mathrm{Ag} / \mathrm{AgCl})$ and for the counter electrode (Pt spiral). A Pt disc which has area of $7.85 \times 10^{-3} \mathrm{~cm}^{2}$ was used as micro working electrode. A Pt electrode with much larger area $\left(A=2.80 \mathrm{~cm}^{2}\right)$ was used as macro working electrode which was used for the preparation of larger amounts of the redox polymer for spectroscopic and DSC investigations. Cyclic voltammetry and differential pulse anodic stripping voltammetry were the main methods used for studying the electrochemical response of anion exchanged films. Differential pulse anodic stripping of the concentrated anions was carried out in $0.1 \mathrm{M}$ aqueous $\mathrm{NaClO}_{4}$ solution.

A PAR Model 173 potentiostat was used together with a PAR Model 175 universal programmer for electrochemical measurements. BBC Goertzt Metrawatt Model X-Y recorder was used for recording current-voltage curves. Differential pulse anodic stripping voltammetry was done using a PAR Model 174A polarographic analyzer together with a Houston Instruments Model 2000 Omnigraphic recorder. Current time curves were recorded on a Cole Parmer 60648 X-t recorder. IR spectra were obtained with a Hitachi Model 270-30 IR spectrophotometer. A Mettler TA 3000 instrument coupled with a DSC 20 was used for DSC measurements.

\section{RESULTS AND DISCUSSION}

The cyclic voltammetric behavior of $\mathrm{PVF}^{+} \mathrm{ClO}_{4}{ }^{-}$film in aqueous and nonaqueous media showed that the type of the solvent and the nature of the counter ion used significantly affect the intensities of the forward and reverse peaks. In acetonitrile solvent with $\mathrm{ClO}_{4}{ }^{-}$as counter ion the peaks due to the oxidation and reduction of redox pair are much more intense than those obtained in aqueous medium with the same counter ion. The peak intensities are reduced considerably when the polymer has $\mathrm{PF}_{6}^{-}$as counter ion in aqueous medium. The different degrees of swelling and the variations of the mobilities of the counter ions account for these intensity changes caused by the solvent and the counter ion, respectively.

IR spectra of the reduced (PVF) and the oxidized $\left(\mathrm{PVF}^{+} \mathrm{ClO}_{4}^{-}\right)$films indicated the existence of the $\mathrm{ClO}_{4}^{-}$as counter ion in the structure of the PVF+ type film (peaks at $622 \mathrm{~cm}^{-1}$ and $1100 \mathrm{~cm}^{-1}$ ) These peaks are absent in the IR spectrum of PVF type film. The DSC measurements also showed the presence of $\mathrm{ClO}_{4}^{-}$in $\mathrm{PVF}^{+}$type film with characteristic sharp decomposition peak at $175^{\circ} \mathrm{C}$. $\mathrm{PVF}^{+} \mathrm{ClO}_{4}^{-}$film has a green color and is soluble in DMF, insoluble in methylene chloride. In contrast the reduced film (PVF) has a yellow color and is soluble in methylene chloride and insoluble in DMF.

The fact that the electron transfer to another depolarizer can take place is demonstrated by the comparative cyclic voltammetric study of anthracene in acetonitrile medium [13]. Anthracene is reduced at the same potentiais on an uncoated and film-coated Pt surfaces. The steady state cyclic voltammograms also revealed that the reduction peak current of anthracene is considerably enhanced on a film-covered surface. About six-fold increase in the reduction peak current value was observed together with an disappearance of the anodic peak due to the oxidation of the anion radical that is electrogenerated during the cathodic scan. IR 
and DSC examination and the change in color and solubility properties of the film after a multisweep cyclic voltammetric scan between $+1.0 \mathrm{~V}$ and $-2.3 \mathrm{~V}$ in anthracene solution indicated that the $\mathrm{ClO}_{4}{ }^{-}$were lost from the polymeric structure, meaning the generation of PVF type film after electroreduction of anthracene. This results can be interpreted in a following way. Anthracene is electroreduced on both uncoated and filmcoated Pt electrodes

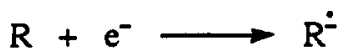

The anion radicals thus produced are stable within the time scale of this cyclic voltammetric experiment so that an anodic peak of almost same intensity is observed when the potential scan is reversed on uncoated $\mathrm{Pt}$ electrode, because of following electrooxidation

$$
\mathrm{R}^{-} \longrightarrow \mathrm{R}+\mathrm{e}^{-}
$$

This anodic peak is absent when the same experiment is carried out with the film-coated Pt electrode. The anthracene reduction current is enhanced due to the following fast homogeneous electron transfer reaction.

$$
\mathrm{PVF}^{+}+\mathrm{R}^{-} \longrightarrow \mathrm{PVF}+\mathrm{R}
$$

As a result catalytic generation of neutral anthracene occurs giving rise to the conversion of considerable amount of the sites in the film from PVF ${ }^{+}$to PVF type. It is important to realize that not all of the $\mathrm{PVF}^{+}$ sites are reduced during the cathodic scan so that there remains enough numbers of $\mathrm{PVF}^{+}$sites in polymer to reduce anthracene radical anions.

The cyclic voltammetric pattern changes also if the electrooxidation peak of anthracene is included during the potential scan [14]. The steady state cyclic voltammograms of anthracene reduction and oxidation taken between $+1.50 \mathrm{~V}$ and $-2.30 \mathrm{~V}$ on an uncoated and coated Pt surfaces showed that, in addition to the enhancement of the anthracene reduction peak, the current due to the anthracene oxidation is also increased substantially. Furthermore the current due to the reduction of protons that are released after electrooxidation of anthracene vanishes.

The mechanism of electrooxidation of anthracene in nonaqueous media is well established. The cation radicals are not stable and the release of protons is the main side reaction which gives rise to some undesired products.

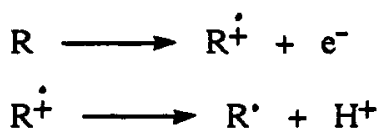

The attack of residual water on neutral radicals produces hydroxy substituted and quinone type end products. The cyclic voltammetry on a film-covered electrode shows that the release of protons does not occur. The catalytic regeneration of neutral anthracene occurs instead. As discussed above PVF ${ }^{+}$sites are converted to PVF type centers during the electroreduction of anthracene. These PVF centers now act as catalytic sites for the generation of neutral anthracene species according to the following homogeneous electron transfer reaction

$$
\mathrm{R}^{+}+\mathrm{PVF} \longrightarrow \mathrm{R}+\mathrm{PVF}^{+}
$$

This redox reaction occurs apparently at a much faster rate than the release of protons from the radical cations.

$\mathrm{PVF}^{+} \mathrm{ClO}_{4}^{-}$film has an ability to exchange its counter ion with some anions in solution according to the following reaction [15].

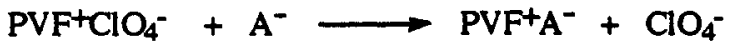

Among the anions studied with respect to their anion exchange properties are iodide, cyanide, thiocyanate and phosphate. The electroactivity of the film itself arising from ferrocenium/ferrocene couple either decreases or vanishes completely depending upon the type and concentration of the exchanging anion. The electroactivity loss is most pronounced in the case of cyanide. Some small fraction of the cyanide ion exchanged causes even crosslinking in the structure of the polymer as evidenced from the major changes occuring in the physical properties such as solubility and thermal stability of the material. 
Incorporation of exchanging anions can be followed spectroscopically. Peaks due to $\mathrm{ClO}_{4}^{-}$at $622 \mathrm{~cm}^{-1}$ and $1100 \mathrm{~cm}^{-1}$ disappear and a new peak at $2080 \mathrm{~cm}^{-1}$ appears in the IR spectrum of the film after thiocyanate uptake. UV spectroscopy can also be used for the same purpose if the colorimetric properties of the film changes as a result of anion exchange. The absorption peaks due to iodide appear in the spectrum after iodide is increased in the structure. The existence of iodide in $\mathrm{PVF}^{+}$film causes the original green color to change to yellow without affecting its solubility properties. If the incorporated anion has its own electroactivity it can be stripped off the polymeric structure anodically. It was shown that depending upon the thickness of the film and the immersion time during the preconcentration step, electroactive anions with concentrations as low as $10^{-10} \mathrm{M}$ can be determined [15].

The concurrent use of catalytic and anion exchange properties of the $\mathrm{PVF}^{+} \mathrm{ClO}_{4}^{-}$film has led to the development of a simple,sensitive, fast responding,stable and low cost electrochemical glucose biosensor [16]. This novel glucose sensor operates under aerobic conditions. Common ingredients encountered in biological fluids such as ascorbic and uric acids cause no noticeable interference, during the operation of this sensor. The working principle of this enzyme electrode is outlined below.

Since enzymes possess negative charges at $\mathrm{pH}$ values above their isoelectric points, they can also be incorporated in the polymeric structure electrostatically through anion exchange

$$
\mathrm{PVF}^{+} \mathrm{ClO}_{4}^{-}+\mathrm{E} \longrightarrow \mathrm{PVF}^{+} \mathrm{E}^{-}+\mathrm{ClO}_{4}^{-}
$$

The electroactivity of the film due to the $\mathrm{PVF}^{+} / \mathrm{PVF}$ redox couple gradually decreases and eventually vanishes as a result of the incorporation of $\mathrm{PO}_{4}{ }^{3}$ ions that are present in the buffer solution containing the enzyme. This enzyme loaded electrode gives a distinct electrooxidation peak at $+0.48 \mathrm{~V}$ vs. SCE when $\mathrm{H}_{2} \mathrm{O}_{2}$ is formed. The peak current values obtained with $\mathrm{PVF}^{+}$coated electrode are much higher than those obtained with the uncoated $\mathrm{Pt}$ electrode. This is because of the existence of a mediators such a ferrocenium sites for the oxidation of $\mathrm{H}_{2} \mathrm{O}_{2}$

$$
\mathrm{H}_{2} \mathrm{O}_{2}+2 \mathrm{PVF}^{+} \longrightarrow \mathrm{O}_{2}+2 \mathrm{PVF}+2 \mathrm{H}^{+}
$$

Consumed ferrocenium sites are catalytically regenerated at the applied potentials,

$$
\text { PVF } \longrightarrow \text { PVF }^{+}+\mathrm{e}^{-}
$$

On an uncoated Pt surface only the catalyzed electrooxidation of $\mathrm{H}_{2} \mathrm{O}_{2}$ occurs, giving rise to much smaller current values.

$$
\mathrm{H}_{2} \mathrm{O}_{2} \longrightarrow \mathrm{O}_{2}+2 \mathrm{H}^{+}+2 \mathrm{e}^{-}
$$

Cyclic voltammetry, carried out with a glucose oxidase loaded electrode when increasing amounts of glucose are added, showed the existence of the $\mathrm{H}_{2} \mathrm{O}_{2}$ oxidation peak with increasing height. $\mathrm{H}_{2} \mathrm{O}_{2}$ which is sensed by the electrode is now produced as a result of the following enzymatic reactions.

$$
\begin{aligned}
& \text { (glucose oxidase) } 0 x+\text { glucose } \longrightarrow \text { (glucose oxidase) } r \text { red }+ \text { gluconic acid } \\
& \text { (glucose oxidase) } r \text { red }+\mathrm{O}_{2} \longrightarrow \text { (glucose oxidase) } \mathrm{ox}+\mathrm{H}_{2} \mathrm{O}_{2}
\end{aligned}
$$

$\mathrm{H}_{2} \mathrm{O}_{2}$ thus produced is oxidized by $\mathrm{PVF}^{+}$sites. The PVF sites are reoxidized and PVF ${ }^{+}$sites are thus regenerated electrochemically as explained above. The role of the molecular oxygen is to act as an oxidant for the regeneration of the oxidized form of the enzyme. The crucial role of $\mathrm{O}_{2}$ in this mechanism is evidenced from another independed experiment. It was found that the peak current value of the $\mathrm{H}_{2} \mathrm{O}_{2}$ oxidation on enzyme loaded electrode was directly proportional to the concentration of dissolved $\mathrm{O}_{2}$ [16].

The current-time responses obtained when a constant potential is applied to the enzyme electrode in solutions containing varying concentrations of glucose was found to be linear up to $30 \mathrm{mM}$ glucose concentration. This amperometric response of the enzyme electrode varies linearly with the thickness of the polymeric film up to a certain thickness after which a saturation value is obtained. The current measured with this enzyme electrode is also linearly dependent upon the amount of the enzyme immobilized in the film. The sensitivity of the electrode described is about two hundred times of greater than the glucose sensors given in literature. This can be very important for ultramicroelectrode biosensor designs for in-vivo measurements. The response of this electrode is maximum at temperatures of physiological fluids which is again an important property for in-vivo applications. 
It is possible to immobilize more than one enzyme in the polymeric structure. When glucose oxidase and invertase are coimmobilized in the film the electrode responds to the presence of sucrose in the solution. This way another low cost, simple, sensitive and stable sensor can be developed [17]. The current-time curves obtained with solutions of varying sucrose concentrations using glucose oxidase/invertase loaded electrode showed a slow rise in current. The invertase catalyzes the conversion of sucrose into $\alpha$-glucose according to,

$$
\text { sucrose }+\mathrm{H}_{2} \mathrm{O} \stackrel{\text { invertase }}{\longrightarrow} \alpha \text {-glucose }+\beta \text {-fructose }
$$

$\alpha$-glucose is converted to $\beta$-glucose usually by using a third enzyme called mutarotase in a reaction named mutarotation

\author{
mutarotase \\ $\alpha$-glucose $\rightleftharpoons \beta$-glucose
}

It is well known that the phosphate ions in the medium can also accelerate the mutarotation reaction to some extent [18]. In the sucrose electrode described here the accelerating effect of the phosphate ions is utilized and the need for the use of mutarotase as the third enzyme is thus eliminated. The slow rise of the current response is the result of the slow conversion of $\alpha$-glucose to $\beta$-glucose with the aid of phosphate ions. Glucose oxidase serves for the generation of $\mathrm{H}_{2} \mathrm{O}_{2}$ as in glucose sensor described above. $\mathrm{H}_{2} \mathrm{O}_{2}$ is here produced from the sequential reactions catalyzed by two enzymes. This sensor responds to sucrose with a good linear amperometric response region up to $55 \mathrm{mM}$ sucrose concentration.

The glucose sensor as well as sucrose sensor described above measure the catalytically enhanced $\mathrm{H}_{2} \mathrm{O}_{2}$ oxidation current in contrast to the most existing sensors which rely on the $\mathrm{O}_{2}$ reduction current measurements.

\title{
ACKNOWLEDGMENTS
}

A. Y. thanks Alexander von Humboldt Foundation for the donation of instruments.

\section{REFERENCES}

1. A. Mertz and A.J. Bard, J. Am. Chem. Soc. , 100, 3222 (1978).

2. K. Itaya and A. J. Bard, Anal. Chem. , 50, 1487 (1978).

3. P. J. Peerce and A.J. Bard, J. Electroanal. Chem., 108, 121 (1980).

4. D.R. Rolison, M. Umana, P. Burgmayer and R. W. Murray, Inorg. Chem., 20, 2996 (1981).

5. P. Daum and R. W. Murray, J. Electroanal. Chem. 103, 289 (1979).

6. P. Daum, J.R. Lenhard, D. Rolison and R. W. Murray, J. Am. Chem. Soc. , 102, 4649 (1980).

7. P. Daum and R. W. Murray, J. Phys. Chem. , 85, 389 (1981).

8. R. J. Nowak,F.A. Schultz, M. Umana, R. Lam and R. W. Murray, Anal. Chem., 52, 315 (1980).

9. Y. Shirota, T. Kahuta and H. Mikawa, Makromol. Chem., 5, 377 (1984) .

10. P.J. Peerce and A. J. Bard, J Electroanal. Chem. , 112, 97 (1980).

11. G. Inzelt and L. Szabo, Electrochim.Acta, 31, 1381 (1986) .

12. P. J. Peerce and A. J. Bard, J. Electroanal. Chem. , 114, 89 (1980).

13. H. Gülce, H. Özyörlik and A. Yıldız, Ber. Bunsenges. Phys. Chem., 98, 228 (1994).

14. H. Gülce, H. Özyörik and A. Yıldız, Ber. Bunsenges. Phys. Chem., 98, 828 (1994).

15. H. Gülce, H. Özyöruk and A. Yıldız, J. Electroanalysis, 7, 178 (1995).

16. H. Gulce, H. Ozyörtlk, S. S. Celebi and A. Yıldız, J. Electroanalytical Chemistry, in press 1995

17. H. Gulce, S. S. Çelebi, H. Özyörtik and A. Yıldız, J. Electroanalytical Chemistry, in press 1995

18. A. Barlikova, J. Svorc and S. Miertus, Anal. Chim. Acta, 247, 83 (1991). 